\title{
EFFICACY AND OPIOID-SPARING EFFECT OF INTERPLEURAL BUPIVACAINE IN PATIENTS UNDERGOING LAPAROSCOPIC CHOLECYSTECTOMY - PROSPECTIVE OBSERVATIONAL STUDY (Running title: Efficacy of inter-pleural bupivacaine in laparoscopy)
}

\author{
Prasath A. $K^{1}$, Senthil Kumar $A^{1 *}$, Mohanhariraj Angamuthammal ${ }^{1}$, Agnes Evangleen ${ }^{1}$ \\ ${ }^{1}$ Dept. Of Anesthesiology, Govt. Mohan Kumaramangalam Medical College, Salem, Tamil Nadu, India
}

Submitted March 23, 2021, Revision received May 22, 2021, Accepted September 5, 2021.

\begin{abstract}
Introduction: Laparoscopic cholecystectomy is considered minimally invasive, but pain following laparoscopy is moderate to severe, leading to increased morbidity and length of hospital stay. Various medications, including opioids, NSAIDs, and techniques like intraperitoneal local anesthetic infiltration, are used. In this study, we investigated interpleural block with bupivacaine for pain relief following laparoscopic cholecystectomy. Methods: A total of 60 patients were included in the study. 30 patients received $20 \mathrm{ml}$ of 0.5\% interpleural bupivacaine (group 1), and 30 patients recieved $20 \mathrm{ml}$ of $0.9 \%$ normal saline (group 2). We recorded visual analog score (VAS), vital signs, and postoperative opioid requirements. Tramadol ( $2 \mathrm{mg} / \mathrm{kg}$ ) was rescue medication if VAS $\geq 5$. Results: Significant difference between study groups was recorded among VAS scores measured at 30 minutes, 1, 2, 6, 10, and 12 hours ( $p$ value < 0.05). The difference in VAS scores at 15 minutes and 14 hours between study groups was insignificant ( $p$ value $>0.05$ ). The number of patients who received tramadol was $9(30 \%)$ patients in group 1 and $29(96.7 \%)$ patients in group 2. The difference in proportion for tramadol intake at 6 hours was significant among study groups (p-value $<0.05$ ). Conclusion: Interpleural bupivacaine $20 \mathrm{ml}$ of $0.5 \%$ used as analgesia reduces post-operative opioid requirement following laparoscopic cholecystectomy. Hence interpleural block can be safely used as a regional technique for pain relief following laparoscopic cholecystectomy.
\end{abstract}

Keywords: laparoscopic cholecystectomy; interpleural block; bupivacaine

\section{Introduction}

A nalgesia requirement for pain control in the post-anaesthesia care unit (PACU) depends on the type of surgery, patients' characteristics, surgery timing, and amount of intraoperative analgesia $^{1}$. Laparoscopic cholecystectomy (LC) is the standard treatment for symptomatic gallstone disease $^{2}$. It is considered a minimally invasive technique characterized by reduced surgical trauma, post-operative pain, respiratory complications, cosmetically smaller incision, and length of hospital stay compared to open surgery ${ }^{3}$.

LC is performed in many centeres as a day-case procedure. Hence, pain control after LC is of utmost importance as moderate to severe pain lengthens the hospital stay resulting in increased morbidity and higher costs ${ }^{4}$. The pain after LC is the amalgamation of three different but clinically separate components; incisional pain/somatic pain, visceral pain /deep intra-abdominal pain, and shoulder pain/referred visceral pain ${ }^{5}$. Opioid use is always related to side effects, such as nausea and vomiting, respiratory depression, and constipation; therefore, studies have investigated the administration of local anesthetic (LA) by various routes ${ }^{6}$.

Previous studies have shown that multimodal analgesic strategies with local infiltration provide strong analgesic effects and reduce the incidence of opioid-related side effects, resulting in faster recovery and shorter hospital stay ${ }^{7}$. The PROSPECT (PROcedure SPECific Postoperative Pain Management) procedure-specific literature review of systematic reviews and RCTs recommends ba- 
sic analgesic techniques: paracetamol NSAIDS and opioids for rescue analgesia only (https://esraeurope.org/pain-management/). Additionally, gabapentinoids, intra-peritoneal local anaesthetic, and transverses abdominals blocks are used. Single-port incision techniques are not recommend$\mathrm{ed}^{8}$. One meta-analysis added more evidence to the role of enhanced recovery after surgery (ERAS) programme and intraperitoneal ropivacaine ${ }^{9}$. A previous study reported that intraperitoneal bupivacaine $(0.125 \%, 80 \mathrm{ml}(100 \mathrm{mg}))$ is more effective compared to levobupivacaine $(0.125 \%, 80 \mathrm{ml}$ (100 $\mathrm{mg})$ ) in decreasing the postoperative pain after $\mathrm{LC}^{10}$. No such studies are reported from patients population in India.

To date, administration of non-steroidal anti-inflammatory drugs (NSAIDs) and narcotics, gas drainages, intraperitoneal saline, and intraperitoneal local anesthetic and opioids were carried out to decrease post-operative pain after LC. However, the use of these methods for reducing pain after LC had a lot of side effects. The clinical significance of pain control after laparoscopic surgery remains controversial. Hence, the present study was undertaken to determine the efficacy and opioid-sparing effect of interpleural bupivacaine for postoperative analgesia in patients undergoing laparoscopic cholecystectomy. Objectives of our study were primarily to evaluate the effectiveness of inter-pleural bupivacaine among patients undergoing elective laparoscopic cholecystectomy and to assess the opioid-sparing effect and postoperative pain relief.

\section{Methods}

A prospective observational study included patients who were indicated for laparoscopic cholecystectomy in the general surgery department at a tertiary care setting. This study was carried for a period of two years, from October 2018 to October 2020. Institutional ethical committee approval and permission from the collaborated department were obtained. All procedures involving human subjects were performed according to Helsinki guidelines. All patients gave informed written consent before enrolment and after discussing the anesthetic options. Details related to the safety and adequacy of pain management techniques were explained priorly to patients, and confidentiality of the subjects was maintained throughout.
All 60 patients who were indicated for laparoscopic cholecystectomy were selected according to universal sampling for the feasibility of the study and were followed for 20 days post-surgery. Patients were allocated into two groups, group 1, which included 30 patients receiving interpleural bupivacaine, and group 2, which included 30 patients receiving interpleural saline. The observer and the subjects were blinded for the drug being administered and the procedure performed. Inclusion criteria were male and females aged 20-60, given written consent to participate in the study, diagnosed with cholelithiasis requiring elective laparoscopic cholecystectomy surgery under general anesthesia, American Society of Anesthesiologists (ASA) grade I and II, body weight between 40-90 kg. Exclusion criteria were ASA grade III and IV, refusal to participate in the study, allergy to local anaesthetic drugs, coagulopathy, an extensive infection at block site, recent pulmonary infections or diseases which include hemothorax, emphysema, bullous lung disease, pleurodesis, as well as any other spinal comorbidities that hampered surgery, and pregnant and nursing women. Intraoperative exclusion criteria were conversion to open cholecystectomy and LC duration longer than 3 hours.

After performing the pre-anaesthetic evaluation and recording detailed history, a complete physical examination was carried out. Complete blood count, random blood sugar, renal function test, blood grouping/typing, HBsAg, HCV, antiretroviral screening tests were done. Patients in group 1 received $20 \mathrm{ml}$ of $0.5 \%$ interpleural bupivacaine. Patients in group 2 received $20 \mathrm{ml}$ of $0.9 \%(\mathrm{NaCl})$ interpleural saline.

The visual analog scale (VAS) and how to rate pain from 1-10 on the scale were clearly explained to all patients participating in the study. All the patients were fasted for 8 hours before the surgical procedure. Premedication consisted of orally used metoclopramide (10 $\mathrm{mg}$ tablet), ranitidine (150 mg tablet), and diazepam (5 mg tablet) on the night before surgery and at 6 am on the morning of surgery with sips of water. On the day of surgery, patients involved in the study were shifted to the premedication room and two $18 \mathrm{G}$ intravenous cannulae were secured for giving intravenous fluids and for the administration of drugs. 
All the patients were premedicated with an injection of glycopyrrolate $(0.2 \mathrm{mg}$ IV) and midazolam $(0.1 \mathrm{mg} / \mathrm{kg} \mathrm{IV})$ in the operative room. The patient's baseline heart rate, blood pressure, $\mathrm{SpO} 2$ were recorded 5 minutes after arriving in the operative room and continuously during surgery via standard monitoring (SpO2, NIBP, HR, ECG, ETCO2). Pre-oxygenation with 100\% oxygen for 3 minutes, was followed by fentanyl injection $(2 \mu \mathrm{g} /$ $\mathrm{kg}$ ). Anaesthesia was induced with propofol $2 \mathrm{mg} /$ $\mathrm{kg}$ IV given in incremental doses until the absence of response to verbal commands. The muscle relaxation was achieved with injection succinylcholine $(2 \mathrm{mg} / \mathrm{kg})$ to facilitate intubation. The airway was secured using a suitable-sized cuffed endotracheal tube. Anesthesia was maintained with nitrous oxide at $3 \mathrm{~L} / \mathrm{min}$, oxygen at $1.5 \mathrm{~L} / \mathrm{min}$ mixture with sevoflurane administered at $1 \%$ inspired concentrations. Ventilation was adjusted to maintain ETCO2 in the range of 30 to $40 \mathrm{~mm} \mathrm{Hg}$. After spontaneous reversal from succinylcholine, muscle relaxation was obtained with injection atracurium is a loading dose of $0.5 \mathrm{mg} / \mathrm{kg}$ followed by maintenance doses of $0.1 \mathrm{mg} / \mathrm{kg}$ IV every 20 minutes. During the intraoperative period, patients received IV crystalloid solutions calculated in accordance with the Holliday Segar formula. The intra-abdominal pressure was maintained at a constant value of $12 \mathrm{~mm} \mathrm{Hg}$. During the closure of the surgical site, both group patients received paracetamol ( $1 \mathrm{~g} \mathrm{IV})$.

At the end of the procedure, after the return of spontaneous ventilation and before extubating the patient, the patient was put in the left lateral decubitus position. The site for needle insertion was cleaned, and the local anesthetic infiltration was done at the site of injection. While breathing spontaneously, a 16 G Tuohy needle was used to puncture the skin of the patient. The needle was inserted just above the eight intercostal space 10 $\mathrm{cm}$ from the spinous process of vertebra in midline of the back; $500 \mathrm{ml}$ of normal saline along with the infusion set was placed approximately $60 \mathrm{~cm}$ above the level of the patient. Under strict aseptic precautions, the three-way connector was connected to the infusion set at its side port and was primed with saline. The other ports are kept closed. Once when space was identified by free flow of saline, the fluid port was closed, and either $20 \mathrm{ml}$ of saline or $20 \mathrm{ml}$ of $0.5 \%$ bupivacaine was injected through the syringe fitted through the other port into the interpleural space. After the installation of the drug into the interpleural space, the needle was then withdrawn and the puncture site plastered with gauze.

At the end of the procedure, the patient was again placed in the supine position. Sevoflurane was discontinued, and an injection of neostigmine $0.05 \mathrm{mg} / \mathrm{kg}$ and glycopyrrolate $10 \mu \mathrm{g} / \mathrm{kg}$ was administered intravenously as a reversal agent for neuromuscular blockade. After achieving adequate spontaneous respirations and the patient was able to obey simple commands, oropharyngeal suctioning was done and tracheal extubation was performed. All the patients were shifted to the post-anesthesia care unit at the end of the surgery. In the postoperative period, pain scores and opioid consumptions at intervals of 15 mins, 30 mins, 1 st hour, 2nd hour, 6 th hour, 10th hour 12th hour and 14th hour were recorded. Intravenous tramadol $2 \mathrm{mg} / \mathrm{kg}$ was used if VAS pain score either 5 or higher.

VAS score was considered as primary outcome variable. Quantitative parameters were verified for the normal distribution between study groups. For normally distributed quantitative parameters, an independent sample t-test (2 groups) was used to compare the means between study groups and a chi-square test was used to compare the categorical variables between study groups using coGuide software, V.1.03. P-value was at $<0.05$ was considered as statistically significant ${ }^{11}$.

\section{Results}

Total 60 patients were included in the final analysis. The mean age was $45.47 \pm 8.81$ years in group 1 and $44.13 \pm 8.54$ years in group 2 (Table 1 ). The majority of them were females in both groups, 21 (70\%) in group 1 and 23 (76.7\%) in group 2 (Table 1). No statistically significant difference was observed in the groups regarding the demographic and anthropometric data, demonstrating the homogeneity of the study population (Table 1).

The mean difference was high in group 1 for the duration of surgery and procedure, systolic and diastolic blood pressure, whereas pulse rate was low in group 1 (Table 2). Complications like nausea and vomiting were less in group 1 compared to group 2. Length of hospital stay and time to mobilize the patient were similar between groups ( $p>$ $0.05)$. The number of patients who received tram- 
Table 1: Comparison of demographic parameters in the study population

\begin{tabular}{|c|c|c|c|}
\hline Parameters & $\begin{array}{l}\text { Group } 1 \\
(N=30)\end{array}$ & $\begin{array}{l}\text { Group 2 } \\
(\mathbf{N}=30)\end{array}$ & $P$-value \\
\hline Age & $45.47 \pm 8.81$ & $44.13 \pm 8.54$ & $0.552^{\mathrm{a}}$ \\
\hline$<35$ years & $4(13.3 \%)$ & $6(20 \%)$ & \multirow{4}{*}{$0.595^{\mathrm{b}}$} \\
\hline 36 to 45 years & $12(40 \%)$ & $12(40 \%)$ & \\
\hline 46 to 55 years & $10(33.3 \%)$ & $9(30 \%)$ & \\
\hline$>55$ years & $4(13.3 \%)$ & $3(10 \%)$ & \\
\hline \multicolumn{4}{|c|}{ Sex } \\
\hline Male & $9(30 \%)$ & $7(23.3 \%)$ & \multirow{2}{*}{$0.340^{\mathrm{b}}$} \\
\hline Female & $21(70 \%)$ & $23(76.7 \%)$ & \\
\hline Height $(\mathrm{cm})$ & $156.63 \pm 4.12$ & $156.47 \pm 4.46$ & $0.881^{\mathrm{a}}$ \\
\hline Weight (kg) & $66.07 \pm 9.54$ & $65.53 \pm 9.24$ & $0.827^{\mathrm{a}}$ \\
\hline
\end{tabular}

${ }^{\mathrm{a}}$ Independent $\mathrm{t}$-test, $\dagger^{\mathrm{b}} \mathrm{Chi}$-square test

adol in group 1 was 9 (30\%) compared to group 2, 15 minutes, 30 minutes, 1, 2, and 6 hours between $29(96.7 \%)(\mathrm{p}<0.05)($ Table 2$)$. The difference in proportion for tramadol intake at 6 hours was significant among study groups $(\mathrm{p}<0.05)$ (Table 2$)$.

The VAS scores at 30 minutes, 1, 2, 6, between study groups were significantly lower in group 1 ( $p$ $<0.001$ ) (Table 3). As the follow-up time increases, the difference in VAS scores between groups becomes lower. The mean difference for heart rate at study groups was statistically significant $(\mathrm{p}<0.05)$ (Table 3). As the follow-up time increases, systolic and diastolic blood pressure was lower in group 1 compared to group 2 (Figure 1) (Figure 2).

\section{Discussion}

According to our knowledge, this is the first study of its kind where we assessed the postoper-

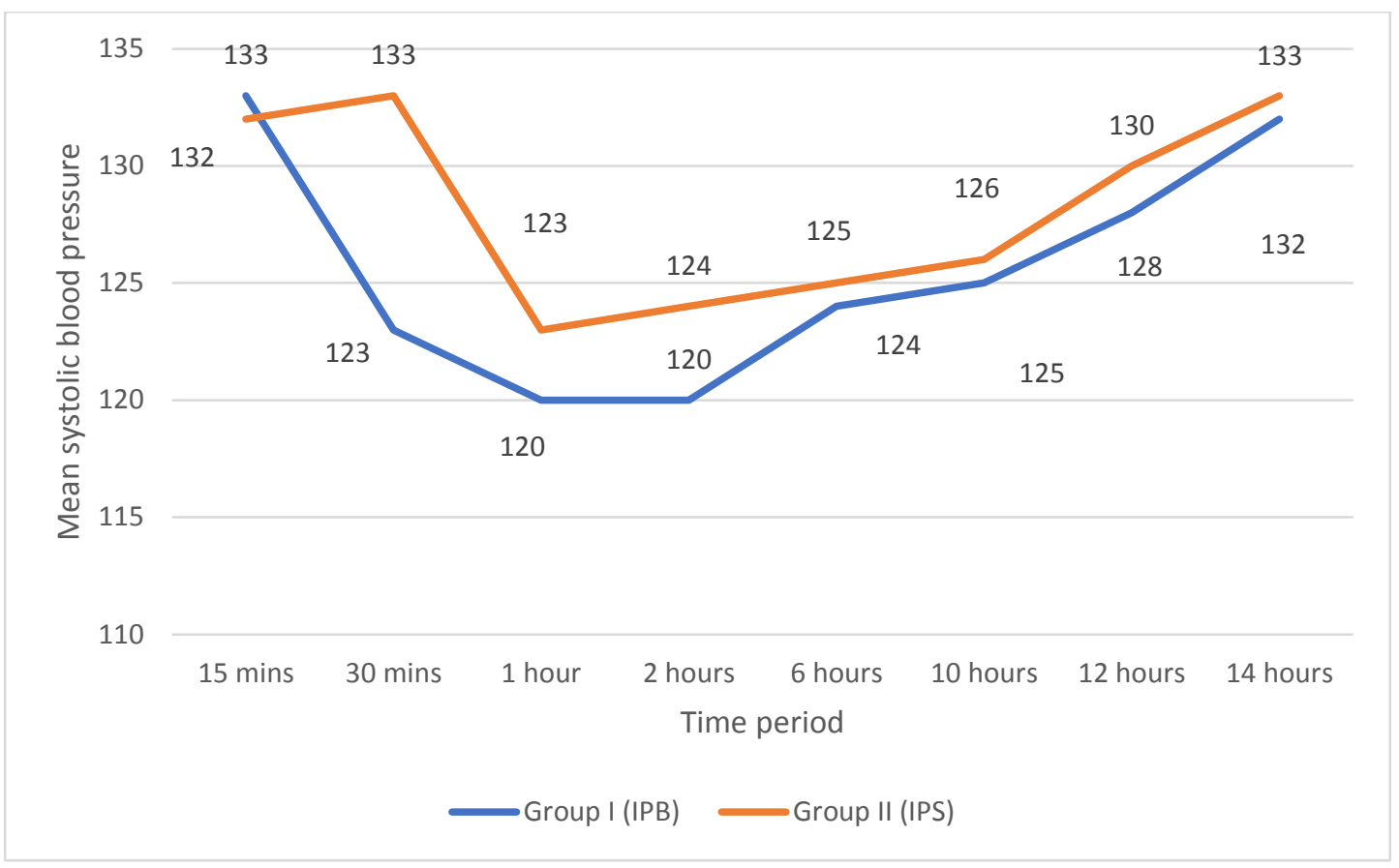

Figure 1: Systolic blood pressure $(\mathrm{mmHg})$ across time $(\mathrm{N}=60)$ 
Table 2: Comparison of clinical parameters between study groups in the study population

\begin{tabular}{|c|c|c|c|}
\hline Clinical parameters & $\begin{array}{l}\text { Group 1 } \\
(\mathbf{N}=30)\end{array}$ & $\begin{array}{l}\text { Group } 2 \\
(\mathbf{N}=30)\end{array}$ & P-value \\
\hline Duration of surgery (minutes) & $133.17 \pm 24.58$ & $131.33 \pm 24.84$ & $0.775^{\mathrm{a}}$ \\
\hline Duration of Procedure (minutes) & $12.23 \pm 2.75$ & $11.57 \pm 2.71$ & $0.348^{\mathrm{a}}$ \\
\hline Systolic blood pressure (mmHg) & $118.23 \pm 5.53$ & $117.33 \pm 5.49$ & $0.529^{\mathrm{a}}$ \\
\hline Diastolic blood pressure (mmHg) & $74.70 \pm 3.82$ & $72.77 \pm 5.16$ & $0.105^{\mathrm{a}}$ \\
\hline Heart rate (beats/min) & $76.37 \pm 5.94$ & $76.97 \pm 6.47$ & $0.710^{\mathrm{a}}$ \\
\hline \multicolumn{4}{|c|}{ Complications } \\
\hline Dizziness & $2(16.7 \%)$ & $2(10 \%)$ & $1.000^{\mathrm{b}}$ \\
\hline Nausea & $7(58.3 \%)$ & $11(55 \%)$ & $0.259^{\mathrm{b}}$ \\
\hline Vomiting & $3(25 \%)$ & $7(35 \%)$ & $0.166^{\mathrm{b}}$ \\
\hline Number patients who received tramadol & $9(30 \%)$ & $29(96.7 \%)$ & $<0.001^{\mathrm{b}}$ \\
\hline \multicolumn{4}{|c|}{ Tramadol consumption $(\mathrm{mg} / \mathrm{kg})$ through the time } \\
\hline 30 mins & $0(0 \%)$ & $25(83.3 \%)$ & $\mathrm{NA}^{\mathrm{c}}$ \\
\hline 1 hours & $0(0 \%)$ & $1(3.3 \%)$ & $\mathrm{NA}^{\mathrm{c}}$ \\
\hline 2 hours & $0(0 \%)$ & $4(13.3 \%)$ & $\mathrm{NA}^{\mathrm{c}}$ \\
\hline 6 hours & $2(6.7 \%)$ & $20(66.7 \%)$ & $<0.001^{\mathrm{b}}$ \\
\hline 10 hours & $0(0 \%)$ & $6(20 \%)$ & $N A^{c}$ \\
\hline 12 hours & $0(0 \%)$ & $8(26.7 \%)$ & $\mathrm{NA}^{\mathrm{c}}$ \\
\hline 14 hours & $7(23.3 \%)$ & $7(23.3 \%)$ & $1.000^{\mathrm{b}}$ \\
\hline Length of hospital stay (days) & 3.5 & 4 & $>0.05$ \\
\hline Time taken to mobilize the patient (hours) & 12.6 & 14.5 & $>0.05$ \\
\hline
\end{tabular}

${ }^{a}$ Independent $t$ test, ${ }^{b}$ chi-square test, ${ }^{c}$ statistical test was not applied as cells had 0 values

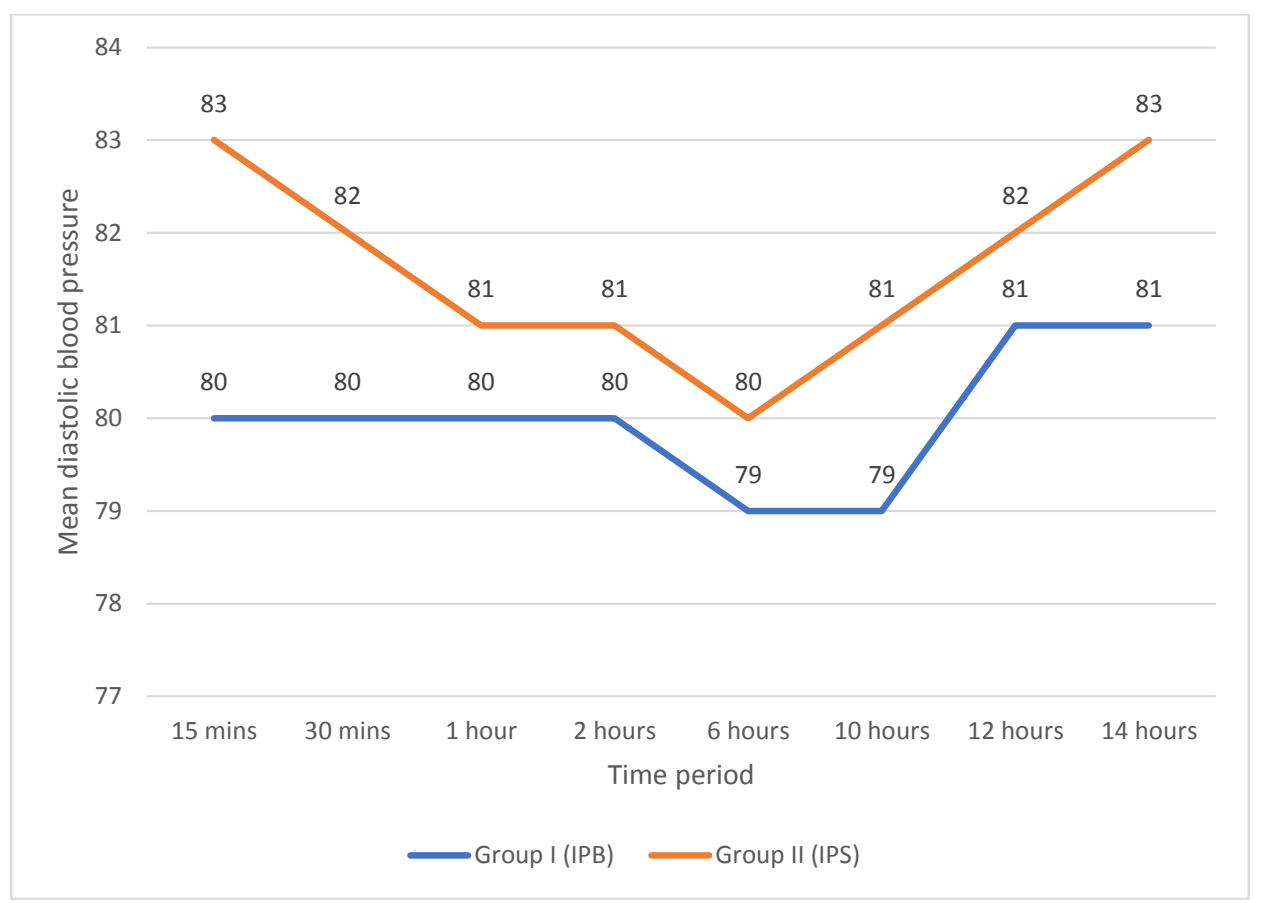

Figure 2: Diastolic blood pressure $(\mathrm{mm} \mathrm{Hg})$ across different time $(\mathrm{N}=60)$ 
Table 3: Comparison of VAS score and heart rate across different periods between study groups

\begin{tabular}{|l|l|l|l|}
\hline Parameters & $\begin{array}{c}\text { Group 1 } \\
(\mathbf{N}=30)\end{array}$ & $\begin{array}{c}\text { Group 2 } \\
(\mathbf{N}=30)\end{array}$ & Unpaired t-test P value \\
\hline \multicolumn{5}{|c|}{ VAS (cm) } \\
\hline 15 mins & $5.47 \pm 1.01$ & $5.93 \pm 1.20$ & 0.109 \\
\hline 30 mins & $0.70 \pm 0.54$ & $5.63 \pm 1.30$ & $<0.001$ \\
\hline 1 hour & $0.40 \pm 0.50$ & $2.70 \pm 0.84$ & $<0.001$ \\
\hline 2 hours & $1.20 \pm 0.81$ & $3.37 \pm 1.27$ & $<0.001$ \\
\hline 6 hours & $2.47 \pm 1.31$ & $5.03 \pm 1.94$ & 0.001 \\
\hline 10 hours & $1.83 \pm 0.75$ & $2.93 \pm 1.55$ & 0.001 \\
\hline 12 hours & $2.40 \pm 1.04$ & $3.57 \pm 1.57$ & 0.839 \\
\hline 14 hours & $3.53 \pm 1.17$ & $3.60 \pm 1.35$ & 0.014 \\
\hline \multicolumn{2}{|c|}{ Heart rate (beats/minute) } & 0.001 \\
\hline 15 mins & $92 \pm 3.8$ & $95 \pm 5.32$ & 0.001 \\
\hline 30 mins & $86 \pm 3.06$ & $94 \pm 4.06$ & 0.048 \\
\hline 1 hour & $81 \pm 3.41$ & $85 \pm 5.41$ & $<0.001$ \\
\hline 2 hours & $81 \pm 2.83$ & $83 \pm 4.63$ & 0.301 \\
\hline 6 hours & $83 \pm 2.89$ & $90 \pm 4.67$ & 0.407 \\
\hline 10 hours & $86 \pm 3.76$ & $85 \pm 3.66$ & $87 \pm 5.11$ \\
\hline 12 hours & $86 \pm 4.11$ & $85 \pm 4.57$ & \\
\hline 14 hours & $86 \pm 3.67$ & & \\
\hline
\end{tabular}

ative pain relief following laparoscopic cholecystectomy and the reduction in opioid consumption with interpleural bupivacaine administration in our tertiary care centre.

We noticed significantly lower VAS pain values in the first six hours and significantly lower tramadol use in bupivacaine group.

There are not many recent studies using inter-pleural block to attenuate post-operative analgesia using bupivacaine; we considered other techniques where bupivacaine was used. A previous clinical study ${ }^{12}$ reported that intra-pleural meperidine reduced post-cholecystectomy pain. In our study, interpleural bupivacaine reduced post-operative pain and the need for additional opioid analgesics. This finding is in comparison to a randomized controlled trial ${ }^{13}$ which indicated that post-operative pain and the number of patients who need analgesics postoperatively was reduced by port insertion site infiltration with bupivacaine compared with the group who received parecoxib.

In the present study, the negative pressure technique was found to be efficacious for the inter-pleural block. There is no difference between air compared to normal saline ${ }^{14}$. In the present study, $20 \mathrm{ml}$ of $0.5 \%$ bupivacaine alone was used in group I. Combining buprenorphine and bupivacaine $(0.25 \%, 15 \mathrm{ml})$ intra-peritoneally effectively relieved postoperative pain for a longer duration after laparoscopic cholecystectomy as compared to the instillation of only bupivacaine ${ }^{15}$.

The incidence of intra- and post-operative complications like dizziness, nausea, vomiting, and length of hospital stay (3.5 days) was less in group 1 than group 2. Similar findings were reported in the study of 5000 patients, with lower incidence of intra- and post-operative complications, and 
92.5\% of patients discharged by post-operative day $3^{16}$. Lower consumption of opioid in patients with interpleural analgesia. This finding was in accordance with another comparative study where interpleural bupivacaine and nalbuphine achieved lower pain scores, lower analgesic consumption over 24 hours, or longer duration of analgesia when compared with local anesthetics alone ${ }^{3}$. On the other side, intraperitoneal instillation of bupivacaine in combination with dexmedetomidine was superior to bupivacaine alone and bupivacaine tramadol ${ }^{17}$. In one study no difference in VAS pain and 24-hour consumption of tramadol was found between groups ${ }^{18}$. Chronic post-operative pain (up to $41 \%$ ) after LC depends on surgical practice, entail finer selection of patients for cholecystectomy. Recently, patient-reported outcome measures (PROMs) are serving tool for finer selection of patients for cholecystectomy that optimizes the surgical complications. It is also a promising tool in evaluating surgical outcomes, as they are known to be consistent after surgery for three months ${ }^{19}$.

Our study has several limitations. The main limitation is the small sample size and single-center study. Another limitation is other associated conditions and comorbidities that were not recorded in the present study but can act as confounders. Our study's observation period was short (14 hours) to reveal potential differences between analgesic durations. Therefore, we recommend further multi-centric randomized clinical trials on large samples and including all confounding factors, which can help the surgeons perform the procedures without any difficulty.

Based on our study results we concluded that interpleural $0.5 \%$ bupivacaine significantly reduces post-operative opioid requirement following laparoscopic cholecystectomy. Hence, technique of interpleural block can be safely used as a regional technique for pain relief following laparoscopic cholecystectomy.

Acknowledgments: Technical support in data entry, analysis, and manuscript editing by „Evidencian Research Associates".

Conflict of interests: The authors declare no conflicts of interest.

Source of funding: The project was self-funded.

\section{References:}

1. Szental JA, Webb A, Weeraratne C et al. Postoperative pain after laparoscopic cholecystectomy is not reduced by intraoperative analgesia guided by analgesia nociception index $\left(\mathrm{ANI}^{\oplus}\right)$ monitoring: A randomized clinical trial. Br J Anaesth. 2015; 114(4):640-5.

2. Ebrahimifard F, Nooraei N. Postoperative pain after laparoscopic cholecystectomy: A randomized clinical trial comparing intraperitoneal bupivacaine versus intravenous pethidine. Surg Laparosc Endosc Percutaneous Tech. 2013; 23(1):88-92.

3. Ali W, Ali N, Sewefy A et al. Comparative study between intraperitoneal bupivacaine and bupivacaine-nalbuphine for postoperative pain relief after laparoscopic cholecystectomy. Res Opin Anesth Intensive Care. 2020; 7(1):57.

4. Shawky AM, Essa A, Emam A. Essa. Effect of Intraperitoneal Ketamine as Postoperative Analgesia in Laparoscopic Cholecystectomy. Egypt J Hosp Med. 2018; 72(3):4224-9.

5. Bisgaard T, Warltier DC. Analgesic Treatment after Laparoscopic Cholecystectomy. Anesthesiology. 2006; 104(4):835-46.

6. Melidi E, Papadima A, Pandazi A et al. Efficacy of Repeated Intraperitoneal Administration of Levobupivacaine in Pain and Opioid Consumption after Elective Laparoscopic Cholecystectomy: A Prospective Randomized Placebo-controlled Trial. Surg Laparosc Endosc Percutaneous Tech. 2016; 26(4):295-300.

7. Liang M, Chen Y, Zhu W et al. Ef fi cacy and safety of different doses of ropivacaine for laparoscopy-assisted in $\mathrm{fi}$ ltration analgesia in patients undergoing laparoscopic cholecystectomy. Medicine (Baltimore). 2020; 46(April 2020):1-7.

8. Barazanchi AWH, Macfater WS, Rahiri J et al. Evidence-based management of pain after laparoscopic cholecystectomy: a PROSPECT review update. Br J Anaesth. 2018; 17:1-17.

9. Yong L, Guang B. Intraperitoneal ropivacaine instillation versus no intraperitoneal ropivacaine instillation for laparoscopic cholecystectomy: A systematic review and meta-analysis. Int J Surg. 2017; 44:229-43.

10. Honca M, Kose EA, Bulus $\mathrm{H}$ et al. The postoperative analgesic efficacy of intraperitoneal bupivacaine compared with levobupivacaine in laparoscopic cholecystectomy. Acta Chir Belg. 2014; 114(3):174-8.

11. BDSS Corp. Released 2020. coGuide Statistics software, Version 1.03, India: BDSS corp. available at https:// www.coguide.in.

12. Mottaghi K, Safari F, Sezari P et al. Effect of intrapleural meperidine on post-operative pain after open cholecystectomy. Tanaffos. 2019; 18(1):79-83.

13. Lin S, Hua J, Xu B et al. Comparison of bupivacaine and parecoxib for postoperative pain relief after laparoscopic cholecystectomy: A randomized controlled trial. Int J Clin Exp Med. 2015; 8(8):13824-9.

14. Antibas PL, do Nascimento Junior P, Braz LG et al. Air versus saline in the loss of resistance technique for identification of the epidural space. Cochrane Database Syst Rev. 2014; 2014(7).

15. Khurana S, Garg K, Grewal A, et al. A comparative study on postoperative pain relief in laparoscopic cholecys- 
tectomy: Intraperitoneal bupivacaine versus combination of bupivacaine and buprenorphine. Anesth Essays Res. 2016; 10(1):23.

16. Bhattarai R, Sulaimankulov R, Dangi SJ et al. Anesthesia for Laparoscopic Cholecystectomy: Experience with 5000 Cases. Ann Int Med Dent Res. 2016; 2(6):20-6.

17. Shukla U, Prabhakar T, Malhotra K et al. Intraperitoneal bupivacaine alone or with dexmedetomidine or tramadol for post-operative analgesia following laparoscopic cholecystectomy: A comparative evaluation. Indian J Anaesth. 2015; 59(4):234-9.
18. Baytar C, Yilmaz C, Karasu D et al. Comparison of ultrasound-guided subcostal transversus abdominis plane block and quadratus lumborum block in laparoscopic cholecystectomy: A prospective, randomized, controlled clinical study. Pain Res Manag. 2019; 2019. 2815301

19. Wennmacker S, Lamberts M, Gerritsen et al. Consistency of patient-reported outcomes after cholecystectomy and their implications on current surgical practice: a prospective multicenter cohort study. Surg Endosc. 2017; 31(1):215-24. 